\title{
¿Es el derecho a la alimentación en los hospitales un derecho humano?
}

\section{Is the right to food in hospitals a human right?}

\author{
Diana Cárdenas, MD, PhD. ${ }^{1}$
}

https://doi.org/10.35454/rncm.v1n2.038

\begin{abstract}
"Esforzarse por garantizar que cada niño, cada mujer y cada hombre tenga una nutrición adecuada y regular, no solo es un imperativo moral y una inversión extremadamente rentable desde el punto de vista económico, sino la aplicación de un derecho humano fundamental."
\end{abstract}

Jacques Diouf, Director General de la FAO, 2005.

Los derechos humanos son un concepto filosófico, jurídico y político según el cual todo ser humano posee derechos universales, inalienables, cualesquiera que sean el derecho positivo en vigor $u$ otros factores como la etnia o la nacionalidad. Cada ser humano sin importar su condición social, raza o religión, tiene derechos «inherentes a su persona, inalienables $y$ sagrados $»^{(1)}$. En consecuencia, el concepto de derechos humanos es por definición universalista e igualitario, incompatible con los sistemas fundados sobre la superioridad de una raza, un pueblo, grupo social o de un individuo. Los derechos humanos son, entonces, prerrogativas propias de los individuos generalmente reconocidos en los países democráticos por la ley, por normas de valor constitucional o por convenciones internacionales, de modo que su respeto está asegurado por todos incluso por el Estado.

La existencia, validez y contenido de los derechos humanos son un tema permanente de debate en particular para ciertos derechos y en ciertos ámbitos como puede ser el derecho a la alimentación en el contexto de la práctica clínica.

El derecho a una alimentación adecuada como un derecho humano fundamental fue reconocido por primera vez en la Declaración Universal de Derechos
Humanos de 1948 como un derecho a un nivel de vida adecuado (Artículo 25):

"Toda persona tiene derecho a un nivel de vida adecuado para la salud, el bienestar y el bienestar de su familia, incluidos los alimentos..."(1).

Este derecho se convirtió en legalmente vinculante (que obliga a las partes) cuando el Pacto Internacional de los Derechos Económicos, Sociales y Culturales (PIDESC) entró en vigor en 1976. Desde entonces, muchos acuerdos internacionales han reiterado el derecho a la alimentación, incluida la Convención sobre la eliminación de todas las formas de discriminación contra la mujer (1979) y la Convención Internacional sobre los Derechos del Niño (1989). Hasta la fecha, 160 Estados han ratificado el PIDESC y, por lo tanto, están legalmente obligados a aplicar sus disposiciones. En el artículo 11 de este Pacto se establece que los Estados partes «reconocen el derecho de toda persona a un nivel de vida adecuado para él y su familia, incluida la alimentación adecuada» y afirma la existencia del derecho de toda persona a estar protegida contra el "hambre y la malnutrición"(2).

Vivir una vida sin hambre es considerado como el mínimo que debe garantizar cada estado independiente del nivel de desarrollo ${ }^{(2)}$. Sin embargo, el derecho a la alimentación no se limita a este aspecto. El Comité de Derechos Económicos, Sociales y Culturales ha definido el derecho a la alimentación en su comentario general No. 12 como:

"El derecho a una alimentación adecuada se realiza cuando cada hombre, mujer y niño, solo o en comunidad, tiene físicamente y económicamente

\footnotetext{
1 Médico Cirujano, Universidad El Bosque.

Diploma Universitario de dietética, nutrición clínica y terapéutica, Hospital Bichat, Denis Diderot, Paris, France.

Magister en Ciencias, Universidad René Descartes, Paris, France.
}

Doctorado en filosofía, Universidad de Franche-Comté, Francia. Magister en Metabolismo y Nutrición, Universidad Paris Diderot, Francia. Magister en Relaciones Internacionales, Políticas internacionales, Universidad de Lyon, Francia. 
en todo momento acceso a alimentos suficientes o a los medios para obtenerlos"(3).

Además, el Comité subraya que el derecho a una alimentación adecuada "no debe interpretarse restrictiva o estrictamente como el derecho a una ración mínima de calorías, proteínas u otros nutrientes específicos". También se deben tener en cuenta otros elementos como las prácticas alimentarias, la educación en temas de higiene, la formación en nutrición, la provisión de cuidados de salud y la lactancia. Esto implica que cada persona debe tener acceso a los alimentos no solo para no sufrir de hambre sino para tener un buen estado de salud y bienestar. Por lo tanto, este derecho engloba dos normas distintas: la primera es el derecho a "una alimentación adecuada", la segunda es que "toda persona esté protegida contra el hambre y la malnutrición”"(3).

Este enfoque del derecho a la alimentación, que ha ido evolucionando desde la década de los años 90 , pretende ir más allá del enfoque de seguridad alimentaria que hasta entonces se ha defendido. Ya no se trata únicamente de la defensa y la promoción de la producción agrícola y de garantizar la disponibilidad de los alimentos; ahora se trata de un derecho a la alimentación que permite proteger a las personas del hambre y la malnutrición para lograr un buen estado de salud. Es decir, se busca proteger el derecho a satisfacer las propias necesidades alimentarias, ya sea produciendo o comprando los productos. Se considera como un cambio radical de perspectiva: el ciudadano beneficiario del derecho a la alimentación ya no es un receptor indefenso, pasivo, un objeto de caridad, y el cual debe "ser alimentado", sino una persona que tiene derecho a beneficiarse de un entorno que le permite alimentarse y, en su defecto, recibir asistencia con dignidad $^{(4)}$.

¿Qué significa que el derecho a la alimentación sea un derecho humano? Desde el punto de vista político, esto implica que los estados tienen ciertos deberes, de los cuales la aplicación efectiva puede ser legítimamente requerida por los individuos. En consecuencia, los Estados deben «respetar, proteger y hacer efectivo el derecho a la alimentación». Por sorprendente que pueda parecer, en el hospital, lugar privilegiado del cuidado a la persona donde se busca la salud y el máximo nivel de bienestar de las personas, este derecho es con frecuencia irrespetado. Prueba de ello es la alta prevalencia de malnutrición que persiste a pesar de distintos esfuerzos tanto nacionales como internacionales y los datos de pacientes no alimentados en estudios como el nutritionDay ${ }^{(5)}$.
Las razones que podrían explicar esta situación, desde mi punto de vista, son tres. Primero, una reflexión epistemológica nos hace entender que el irrespeto del derecho a la alimentación puede deberse a la falta del reconocimiento de la nutrición como una disciplina propiamente clínica. El alejamiento de esta disciplina de las aulas y de la formación práctica de los médicos y otros profesionales de la salud podría tener como consecuencia la invisibilidad de la problemática de la malnutrición. Como resultado, el derecho a la alimentación no sería respetado porque es $\ll$ mal (re) conocido ${ }^{(6)}$.

A esta explicación se suma una segunda cuyo fundamento es ético: los cuidados nutricionales, en particular la terapia nutricional, raramente se consideran como un cuidado propiamente dicho (cuidado en el sentido del "care"). Esto implica que, cuando el médico prescribe una nutrición artificial, prescribe un medicamento que implica un gesto técnico desprovisto de cualquier simbolismo y representación socio cultural inherente a la alimentación y cuyo único objetivo es ayudar en la mejoría clínica del paciente. Es decir, la nutrición es considerada como un tratamiento (en el sentido de «cure") dejando de lado el sentido del "care". De esta manera se invoca el derecho a la salud, pero se descuida el derecho a la alimentación. Por lo tanto, la atención del paciente en su integridad (biológica, psicológica y social) es solo parcial. La dignidad del paciente está en juego.

Finalmente, considero que la ausencia de una terapia nutricional oportuna y óptima en los hospitales y el consecuente no respeto del derecho a la alimentación de las personas también tienen una explicación en la manera como se concibe este derecho en el contexto clínico. ¿Cómo debe entenderse el derecho a la alimentación en el contexto clínico? En otras palabras, ¿se debe garantizar el derecho de las personas a «alimentarse» 0 a ser «alimentados»? Recordemos que en el ambiente político se considera que el beneficiario del derecho a la alimentación es una persona con un papel activo a la que el Estado debe proporcionar un entorno propicio para permitirle «alimentarse a sí mismo»y, en su defecto, recibir asistencia con dignidad. En el contexto clínico, el derecho a la alimentación debe concebirse como el derecho a recibir una terapia nutricional oportuna y óptima, es decir, "a ser alimentado" y debe estar garantizado por el Estado y los cuidadores.

Por un lado, el estado y los legisladores deben garantizar el acceso y la disponibilidad de alimentos en el hospital. Esto implica, en primer lugar, alimentos provistos y preparados en el hospital y los productos de 
nutrición artificial que son el resultado de una producción industrial. Este acceso a la nutrición debe ser tanto económico como físico. Acceso económico porque los productos deben venderse a un costo razonable. Los precios de los productos de nutrición artificial tienen un costo muy alto, lo que pone en considerable peligro el respeto de este derecho. Acceso físico, que debería permitir a todos, incluidos los pacientes en el hospital, obtener alimentos. Esto implica favorecer los medios para que las instituciones hospitalarias puedan proporcionar atención nutricional desde el sistema de salud a todas las instancias incluida la nutrición artificial a domicilio. Finalmente, la dieta debe ser adecuada, dependiendo del tipo de paciente, su estado de salud y necesidades metabólicas, pero también respetando los códigos culturales (prohibiciones religiosas, por ejemplo). A estas tres características de disponibilidad, accesibilidad y nutrición adecuada, se agrega la noción de sostenibilidad. Esto es, en el contexto político, una sostenibilidad que es a la vez ecológica y alimentaria. En el contexto clínico, la sostenibilidad sería farmacológica y nutricional. Además, del mismo modo que en el contexto político, es importante garantizar que las generaciones futuras puedan beneficiarse del derecho a la alimentación en el contexto clínico. Esto podría implicar políticas regulatorias y estándares aplicados a la industria farmacéutica, lo que conlleva a cuestionar las políticas concernientes a los productos de nutrición artificial.

Por otro lado, el derecho a una terapia nutricional oportuna y óptima debe guiar la acción de los responsables. Se trata de defender el derecho de cada persona enferma a «ser alimentado». Más específicamente, el derecho a recibir los requerimientos nutricionales a través de una terapia nutricional oportuna, óptima y de calidad, en un contexto que respalde la dimensión emocional, simbólica y social de la alimentación. Debe enfatizarse que esto no debe ser considerado como un acto de caridad, como lo fue cuando se alimentaba a los enfermos en el hospital durante la Edad Media. Por el contrario, debe considerarse como un cuidado que se integra al tratamiento general de los pacientes hospitalizados los cuales pueden ser doblemente vulnerables porque experimentarán hambre y desnutrición.

En consecuencia, los médicos, los nutricionistas, los enfermeros y otros profesionales de la salud deben hacer cumplir el derecho a la alimentación a través de una terapia nutricional oportuna y óptima. Esto se concretiza al establecer un plan de terapia nutricional adaptado al paciente teniendo en cuenta los posibles beneficios (respeto del principio de beneficencia), los riesgos potenciales y considerando que puede detenerse en cualquier momento según la evolución del paciente (respeto por el principio de no maleficencia), además de privilegiar el ofrecimiento de la nutrición oral cuando sea posible y relevante. La terapia nutricional no debe ser excesiva o convertirse en encarnizamiento terapéutico y debe tener en cuenta los deseos del paciente y la familia (respeto del principio de autonomía). Los beneficios incluyen no solo beneficios clínicos, sino también beneficios para la calidad de vida y la perspectiva emocional y social. Esto debe reflejarse en un profesional de la salud competente con los conocimientos técnicos y las habilidades para realizar una adecuada terapia y para tener en cuenta los antecedentes personales y familiares, estando atentos a los deseos, las expectativas y el proyecto de vida de cada paciente. Por lo tanto, esto implica no solo considerar los beneficios y riesgos clínicos y nutricionales de la nutrición, sino también su valor simbólico, social, familiar y cultural. El profesional de la nutrición debe concebirla bajo un enfoque más amplio y considerar al paciente no como un simple cuerpo con órganos enfermos, sino como una persona apreciada en forma holística. Respetar el derecho a la terapia nutricional en los hospitales implica diseñar un lugar privilegiado para la nutrición en la preservación de la dignidad humana cuando se trata y cuida a una persona enferma.

En este contexto, así como de una manera general, el respeto por los derechos humanos y la dignidad no son valores abstractos, sino que tienen una dimensión práctica «que definen un orden social y nos ponen en relación unos con otros a cargo de obligaciones recíprocas" ${ }^{(7)}$. Es por esto que en este número de la Revista hemos decidido darle un lugar central a la Declaración internacional de Cancún sobre el derecho a la nutrición en los hospitales, firmada por los países miembros de la FELANPE en el año 2008. Este instrumento político es un intento por concretizar, en el contexto Latinoamericano, el ideal de elevar la terapia nutricional al nivel de un derecho humano. Se fundamenta en una concepción de la nutrición clínica como una disciplina interdisciplinaria, donde la terapia nutricional se administre a través del cuidado nutricional el cual implica distintas etapas que inician con el tamizaje nutricional. Pone de manifiesto la necesidad de reforzar la investigación y la educación en pregrado, posgrado y educación continua, así como la elaboración de guías y protocolos propios del continente. Una década después, este instrumento debe ser analizado y actualizado para que tenga un impacto político real que nos permita luchar contra 
el hambre en el hospital y mejorar el estado nutricional, la salud y la calidad de vida del pueblo latinoamericano.

\section{Referencias bibliográficas}

1. Declaración Universal de Derechos Humanos. Adoptada y proclamada por la Asamblea General en su resolución 217 A (III), de 10 de diciembre de 1948. Disponible : http://www. un.org/en/universal-declaration-human-rights/ Consultado el 1 de Agosto 2018.

2. Fao, LE DROIT À L'ALIMENTATION Le temps d'agir Avancées et enseignements tirés lors de la mise en application, 2012. Disponible: http://www.fao.org/docrep/016/i2250f/ i2250f.pdf Consultado el 30 de Julio 2018.

3. Le droit à l'alimentation, organisation des nations unies pour l'alimentation et l'agriculture, Rome, 2006. Disponible : http://www.fao.org/3/a-ah189f.pdf. Consultado el 1 de Agosto 2018.
4. Directeur général de la FAO, Jacques Diouf, 2007. Disponible: http://www1.montpellier.inra.fr/aide-alimentaire/images/ Droit_a_lalimentation/Le_droit_a_l_alimentation notions_generales.pdf. Consultado el 1 de Agosto 2018.

5. Comité des droits économiques, sociaux et culturels, Observation générale 12, Le droit à une nourriture suffisante. E/C.12/1999/5, par. 6. Disponible: https://europa.eu/capacity4dev/file/13174/. Consultado el 1 de Agosto 2018.

6. Theilla M, Grinev M, Kosak S, Hiesmayr M, Singer P. Fight against malnutrition: The results of a 2006-2012 prospective national and global nutritionDay survey. nutritionDay Israel Working Group. Clin Nutr ESPEN. 2015; 10(2):e77-e82. doi: 10.1016/j.clnesp.2015.01.002.

7. Crenn P. Le droit à la nutrition: un droit de l'homme à promouvoir et à défendre. Nutrition Clinique et Métabolique. 2009 ;23. p.172-81.

8. Hirsch E, Mann JM. Droits de l'homme et respect de la personne, En: E. Hirsch, Traité de Bioéthique, Tome I, Fondements, principes repères, Toulouse, Eres, 2010. p. 249. 